\title{
Tool flank wear model and parametric optimization in end milling of metal matrix composite using carbide tool: Response surface methodology approach
}

\author{
R. Arokiadass*, K. Palaniradja and N.Alagumoorthi
}

Department of Mechanical Engineering, Pondicherry Engineering College, Puducherry- 605 014, Puducherry, India

\begin{tabular}{|c|c|}
\hline ART I C L E I N F O & A B S T R A T \\
\hline $\begin{array}{l}\text { Article history: } \\
\text { Received } 28 \text { October } 2011 \\
\text { Accepted December, } 52011 \\
\text { Available online } \\
8 \text { December } 2011 \\
\text { Keywords: } \\
\text { End Milling } \\
\text { Metal Matrix Composite } \\
\text { Response surface methodology } \\
\text { Tool flank wear } \\
\text { Optimization } \\
\text { Contour plots }\end{array}$ & $\begin{array}{l}\text { Highly automated } \mathrm{CNC} \text { end milling machines in manufacturing industry requires reliable model } \\
\text { for prediction of tool flank wear. This model later can be used to predict the tool flank wear } \\
\text { (VBmax) according to the process parameters. In this investigation an attempt was made to } \\
\text { develop an empirical relationship to predict the tool flank wear (VBmax) of carbide tools while } \\
\text { machining LM } 25 \mathrm{Al} / \mathrm{SiCp} \text { incorporating the process parameters such as spindle speed (N), feed } \\
\text { rate (f), depth of cut (d) and various } \% \text { wt. of silicon carbide (S). Response surface } \\
\text { methodology (RSM) was applied to optimizing the end milling process parameters to } \\
\text { attain the minimum tool flank wear. Predicted values obtained from the developed model and } \\
\text { experimental results are compared, and error }<5 \text { percent is observed. In addition, it is concluded } \\
\text { that the flank wear increases with the increase of SiCp percentage weight in the MMC. }\end{array}$ \\
\hline
\end{tabular}

(C) 2012 Growing Science Ltd. All rights reserved

\section{Introduction}

To realize full automation in machining, computer numerically controlled (CNC) machine tools have been implemented during the past decades. CNC machine tools require less operator input, provide greater improvements in productivity, and increase the quality of the machined part. End milling is the most common metal removal operation encountered. It is widely used to mate with other part in die, aerospace, automotive, and machinery design as well as in manufacturing industries.

The machining of MMCs is very difficult due to the highly abrasive and intermittent nature of the reinforcements. Metal matrix composites (MMC) are a relatively new class of materials characterized by lighter weight and greater strength and wear resistance than those of conventional materials. Due to their superior strength and stiffness, MMCs have good potential for application in the automotive and aerospace industries (Kenned et al. (1997), Ravikiran et al. (1997), Allision et al. (1993).

To study the difficulties in machining of MMCs, previous investigations on the machinability of MMCs have covered the effects of machining parameters and the properties of MMCs on the tool wear and the mechanism of the tool wear. Channakesavarao et al. (2000) experimented with different cutting tools. They reported that the crater wear was not appreciable in K10 tools, and it had superior wear resistance and produced continuous chips. Yuan and Dong (1993) investigated the effect of reinforcement volume percentage, cutting angle, feed rate, and speed on the surface integrity in ultra precision diamond turning of MMCs. Davim (2003) examined the influence of cutting speed, feed rate, and cutting time on turning MMCs (A356/20SiCp-T6) using

* Corresponding author Tel: +91-9791488706

E-mail: raja_arokiadass@yahoo.com (R.Arokiadass)

(C) 2012 Growing Science Ltd. All rights reserved. doi: $10.5267 /$ j.ijiec.2011.12.002 
polycrystalline diamond (PCD) cutting tools based on the techniques of Taguchi. Palanikumar and Karthikeyan (2007) investigated the factors influencing the surface roughness on the machining of $\mathrm{Al} / \mathrm{SiC}$ particulate composites using tungsten carbide tool inserts (K10). Dabade et al. (2007) studied the surface integrity as a function of process parameters and tool geometry by analyzing cutting forces, surface finish, and microstructures of the machined surfaces on $\mathrm{Al} / \mathrm{SiC} / 10 \mathrm{p}$ and $\mathrm{Al} / \mathrm{SiC} / 30 \mathrm{p}$ composites using cubic boron nitride (CBN) inserts. Palanikumar and Davim (2009) made an attempt to assess the factors influencing tool wear on the machining of glass fibre-reinforced plastics composites by coated cement carbide tools using the analysis of variance (ANOVA). Most of the above studies showed that the wear characteristics of various tool materials based on cutting parameters and surface finish during the machining of aluminium based composites reinforced with $\mathrm{SiC}$ particles were investigated. Estimation of tool wear during CNC milling using neural network-based sensor fusion was implemented by Ghosh et.al (2007). Cho and Ko (1993) estimated tool wear length in finish milling using a fuzzy inference algorithm. Ning and Veldhuis(2006) analyzed mechanistic modeling of ball end milling including tool wear. Prediction of flank wear by using back propagation neural network modeling when cutting hardened $\mathrm{H}-13$ steel with chamfered and honed CBN tools is used by Ozel and Nadgir (2002)

From the literature it is found that the end milling of Al-MMC is an important area of research. Hence, the main objective of the present work is to investigate the tool flank wear of carbide tools in the machining of the various \%wt. of $\mathrm{SiC}_{\mathrm{p}}$ particle-reinforced LM25 aluminum alloy composites which were produced by a stir casting method and to develop a mathematical model for tool flank wear using the selected process parameters. The experimental results were given with a comparison between experimental values and model predicted values and also given the percentage of error. In addition the tool flank wear in end milling of LM25 $\mathrm{Al} / \mathrm{SiC}_{\mathrm{p}}$ metal matrix composite with different contents of $\mathrm{SiC}_{\mathrm{p}}$ particles $(5,10,15,20$ and $25 \mathrm{wt} \%)$ is investigated.

\section{Experimental work}

In the present experimental study, the material to be machined was LM25 $\mathrm{Al}$ alloy reinforced with $\mathrm{SiC}_{\mathrm{p}}$ particles, at a composition of 5\%wt., $10 \%$ wt., $15 \%$ wt., $20 \%$ wt. and $25 \%$ wt. and of $25 \mu \mathrm{m}$ particle size. The dimensions of the specimens were of $100 \mathrm{~mm} \times 50 \mathrm{~mm} \times 40 \mathrm{~mm}$. The composition of the LM25 Al alloy specimen is presented in Table 1. Computer numerically controlled (CNC) vertical milling machine was used to machine $\mathrm{LM} 25 \mathrm{Al} / \mathrm{SiC}_{\mathrm{p}}$. A carbide tools $(12 \mathrm{~mm}$ diameter; 4 flutes) were chosen for the experiment. The important factors influencing the tool flank wear $\left(\mathrm{VB}_{\max }\right)$ and their levels are presented in Table 2.

Table 1

Chemical composition of LM25 aluminum alloy

\begin{tabular}{llllllll}
\hline Material & $\mathrm{Si}$ & $\mathrm{Mg}$ & $\mathrm{Mn}$ & $\mathrm{Fe}$ & $\mathrm{Cu}$ & $\mathrm{Ni}$ & $\mathrm{Ti}$ \\
\hline LM25 Al alloy & 7 & 0.33 & 0.3 & 0.5 & 0.1 & 0.1 & 0.2 \\
\hline
\end{tabular}

Table 2

Experimental parameters and their levels

\begin{tabular}{lllllllll}
\hline \multirow{2}{*}{ No } & \multirow{2}{*}{ Factor } & \multirow{2}{*}{ Unit } & \multirow{2}{*}{ Notation } & Levels & & & & \\
\cline { 5 - 8 } & & & & $(-2)$ & $(-1)$ & 0 & $(+1)$ & $(+2)$ \\
\hline 1 & Spindle speed & RPM & $N$ & 2000 & 2500 & 3000 & 3500 & 4000 \\
2 & Feed rate & $\mathrm{mm} / \mathrm{rev}$ & $f$ & 0.02 & 0.03 & 0.04 & 0.05 & 0.06 \\
3 & Depth of cut & $\mathrm{mm}$ & $d$ & 0.5 & 1 & 1.5 & 2 & 2.5 \\
4 & Silicon Carbide & $\% \mathrm{wt}$ & $S$ & 5 & 10 & 15 & 20 & 25 \\
\hline
\end{tabular}

As the range of individual factor was wide, a central composite rotatable four-factor, five-level factorial design matrix was selected. The experimental design matrix (Table 3), consisting of 31 sets of coded conditions and comprising a full replication four-factor factorial design of 16 points, 8 star points, and 7 center points, was used. The upper and lower limits of the parameters were coded as +2 and -2 , respectively. The coded values for intermediate levels can be calculated by 
where $X i$ is the required coded value of a variable $X$ and $X$ is any value of the variable from $X_{\min }$ to $X_{\max }$. As prescribed by the design matrix, machining has been carried out for fixed time interval. The flank wear $\left(\mathrm{VB}_{\max }\right)$ was measured by using Metzer tool maker's microscope.

\section{Table 3}

Experimental design matrix and results

\begin{tabular}{|c|c|c|c|c|c|c|c|}
\hline \multirow{2}{*}{ Ex. No. } & \multicolumn{4}{|c|}{ Coded values } & \multicolumn{2}{|c|}{ Tool Flank wear $\mathrm{VB}_{\max }(\mathrm{mm})$} & \multirow{2}{*}{$\%$ Error } \\
\hline & $N$ & $\bar{f}$ & $\bar{d}$ & $\bar{S}$ & Experimental & Predicted & \\
\hline 1. & -1 & -1 & -1 & -1 & 0.224 & 0.219 & 2.28 \\
\hline 2. & 1 & -1 & -1 & -1 & 0.284 & 0.281 & 1.06 \\
\hline 3. & -1 & 1 & -1 & -1 & 0.258 & 0.255 & 1.17 \\
\hline 4. & 1 & 1 & -1 & -1 & 0.291 & 0.292 & -0.34 \\
\hline 5. & -1 & -1 & 1 & -1 & 0.235 & 0.238 & -1.26 \\
\hline 6. & 1 & -1 & 1 & -1 & 0.294 & 0.293 & 0.34 \\
\hline 7. & -1 & 1 & 1 & -1 & 0.270 & 0.268 & 0.74 \\
\hline 8. & 1 & 1 & 1 & -1 & 0.297 & 0.297 & 0.00 \\
\hline 9. & -1 & -1 & -1 & 1 & 0.338 & 0.335 & 0.89 \\
\hline 10. & 1 & -1 & -1 & 1 & 0.407 & 0.4041 & 0.71 \\
\hline 11. & -1 & 1 & -1 & 1 & 0.377 & 0.373 & 1.07 \\
\hline 12. & 1 & 1 & -1 & 1 & 0.422 & 0.416 & 1.44 \\
\hline 13. & -1 & -1 & 1 & 1 & 0.358 & 0.352 & 1.70 \\
\hline 14. & 1 & -1 & 1 & 1 & 0.413 & 0.413 & 0.00 \\
\hline 15. & -1 & 1 & 1 & 1 & 0.384 & 0.384 & 0.00 \\
\hline 16. & 1 & 1 & 1 & 1 & 0.419 & 0.419 & 0.00 \\
\hline 17. & -2 & 0 & 0 & 0 & 0.262 & 0.266 & -1.50 \\
\hline 18. & 2 & 0 & 0 & 0 & 0.361 & 0.363 & -0.55 \\
\hline 19. & 0 & -2 & 0 & 0 & 0.314 & 0.317 & -0.94 \\
\hline 20. & 0 & 2 & 0 & 0 & 0.357 & 0.359 & -0.55 \\
\hline 21. & 0 & 0 & -2 & 0 & 0.309 & 0.317 & -2.52 \\
\hline 22. & 0 & 0 & 2 & 0 & 0.341 & 0.339 & 0.58 \\
\hline 23. & 0 & 0 & 0 & -2 & 0.211 & 0.211 & 0.00 \\
\hline 24. & 0 & 0 & 0 & 2 & 0.443 & 0.449 & -1.33 \\
\hline 25. & 0 & 0 & 0 & 0 & 0.322 & 0.324 & -0.61 \\
\hline 26. & 0 & 0 & 0 & 0 & 0.328 & 0.324 & 1.23 \\
\hline 27. & 0 & 0 & 0 & 0 & 0.319 & 0.324 & -1.54 \\
\hline 28. & 0 & 0 & 0 & 0 & 0.326 & 0.324 & 0.61 \\
\hline 29. & 0 & 0 & 0 & 0 & 0.323 & 0.324 & -0.30 \\
\hline 30. & 0 & 0 & 0 & 0 & 0.327 & 0.324 & 0.92 \\
\hline 31. & 0 & 0 & 0 & 0 & 0.329 & 0.324 & 1.54 \\
\hline
\end{tabular}

\section{Response surface methodology}

Response surface methodology is a mathematical method used investigating problems in which several independent variables affect a dependent variable or response and the aim is to optimize the response (Ozel \& Nadgir, 2002). In many experimental conditions, it is possible to represent independent factors in quantitative form as given in Eq. (2). Then these factors can be regarded as having a functional relationship or response as follows:

$Y=\Phi\left(x_{1}, x_{2} \ldots \ldots x_{k}\right) \pm e_{r}$

Between the response $\mathrm{Y}$ and $x_{1}, x_{2} \ldots \ldots x_{k}$ of $k$ quantitative factors, the function $\Phi$ is called the response surface or response function. The residual $e_{r}$ measures the experimental errors. For a given set of independent variables, a characteristic surface is responded. When the mathematical form of $\Phi$ is not known, it can be approximated satisfactorily within the experimental region by a polynomial. In the present investigation, RSM 
has been applied for developing the mathematical model in the form of multiple regression equations for the quality characteristic of the end milling of LM25 aluminum alloy composites. In applying the RSM, the independent variable was viewed as a surface to which a mathematical model is fitted. Representing the tool flank wear $\left(\mathrm{VB}_{\max }\right)$, the response is a function of spindle speed $(N)$, feed rate $(f)$, depth of cut $(d)$ and \%wt. of silicon carbide $(S)$; it can be expressed as

$\mathrm{VB}_{\max }=f\{N, f, d, S\}$.

The second-order polynomial (regression) equation used to represent the response surface VBmax is given by

$\mathrm{VB}_{\max }=b_{0}+\Sigma b_{i} X_{i}+\Sigma b_{i i} X_{i}^{2}+\Sigma b_{i j} X_{i} X_{j}$,

and for four factors, the selected polynomial could be expressed as:

$\mathrm{VB}_{\max }=b_{0}+b_{1} N+b_{2} f+b_{3} d+b_{4} S+b_{12} N f+b_{13} N d+b_{14} N S+b_{23} f d+b_{24} f S+b_{34} d S+b_{11} N^{2}+b_{22} f^{2}+b_{33} d^{2}+b_{44} S^{2}$

where $b_{0}$ is the average of the responses, and $b_{1}, b_{2}, b_{3}, \ldots, b_{44}$ are regression coefficients (Murti, 1986) that depend on the respective linear, interaction, and squared terms of factors.

\section{Mathematical modeling of tool flank wear $\left(\mathrm{VB}_{\max }\right)$}

Based on Eq. (5), the effects of the above mentioned process parameters on the magnitude of the tool flank wear $\left(\mathrm{VB}_{\max }\right)$ have been evaluated by computing the values of the coefficient of Eq. (5) was calculated using Minitab Software. The significance of each coefficient was determined by Student's $t$ test and $p$ values, which are listed in Table 4 . The values of $p$ less than 0.05 (i.e., $\mathrm{p}=0.05$ or $95 \%$ confidence), which indicates that the model is considered statistically significant. In this case, $N, f, S, N^{2}, f^{2}$ and $N^{*} f$ are significant model terms and $d$ has less influence on tool flank wear. The values greater than 0.10 indicate that the model terms are not significant. The final empirical relationship was constructed using only these coefficients, and the developed final empirical relationship is given below:

$$
\begin{aligned}
& \mathrm{VB}_{\max }=-0.2551+(0.0002 N)+(2.4923 f)+(0.0404 d)+(0.0084 S)+\left(34.4196 f^{2}\right)+\left(0.0033 d^{2}\right)+ \\
& \left(0.0001 S^{2}\right)-(0.0013 N f)-(0.3125 f d)+(0.0088 f S)-(0.0002 d S)
\end{aligned}
$$

The experimental values were compared with the predicted values and the error percentage was calculated, and it is presented in Table 3. Analysis of variance (ANOVA) technique was used to check the adequacy of the developed empirical relationship in Table 5.

\section{Table 4}

Estimated Regression Coefficients for Tool Flank wear $\left(\mathrm{VB}_{\max }\right)$

\begin{tabular}{llll}
\hline Term & Coefficient & T-value & p-value \\
\hline Constant & -0.2551 & -4.124 & $<0.001$ \\
$N$ & 0.0002 & 6.411 & $<0.000$ \\
$f$ & 2.4923 & 2.205 & $<0.042$ \\
$d$ & 0.0404 & 1.880 & 0.078 \\
$S$ & 0.0084 & 3.927 & $<0.001$ \\
$N^{2}$ & -0.0000 & -2.878 & $<0.011$ \\
$f^{2}$ & 34.4196 & 3.873 & $<0.001$ \\
$d^{2}$ & 0.0033 & 0.919 & 0.372 \\
$S^{2}$ & 0.0001 & 1.482 & 0.158 \\
$N^{*} f$ & -0.0013 & -5.418 & $<0.000$ \\
$N^{*} d$ & -0.0000 & -1.631 & 0.123 \\
$N^{*} S$ & 0.0000 & 1.315 & 0.207 \\
$f^{*} d$ & -0.3125 & -1.315 & 0.207 \\
$f^{*} S$ & 0.0088 & 0.368 & 0.718 \\
$d^{*} S$ & -0.0002 & -0.473 & 0.642 \\
\hline PRESS $=0.00173501$ & $\mathrm{R}-\mathrm{Sq}(\mathrm{pred})=98.34 \%$ & & \\
$\mathrm{R}-\mathrm{Sq}=99.65 \%$ & $\mathrm{R}-\mathrm{Sq}(\mathrm{adj})=99.35 \%$ & &
\end{tabular}


Table 5

Test result of ANOVA

\begin{tabular}{llllll}
\hline Source of variation & Degree of freedom & Sum of squares & Mean sum of squares & $F$-value & p-value \\
\hline Regression & 14 & 0.103963 & 0.007426 & 328.73 & 0.000 \\
Linear & 4 & 0.102512 & 0.000268 & 11.88 & 0.000 \\
Square & 4 & 0.000642 & 0.000160 & 7.10 & 0.002 \\
Interaction & 6 & 0.000809 & 0.000135 & 5.97 & 0.002 \\
Residual Error & 16 & 0.000361 & 0.000023 & & \\
Lack of fit & 10 & 0.000283 & 0.000028 & 2.15 & \\
Pure Error & 6 & 0.000079 & 0.000013 & & \\
\hline Total & 30 & 0.104325 & & & \\
\hline
\end{tabular}

In this investigation, the desired level of confidence was considered to be $95 \%$. The relationship may be considered to be adequate, which provides that the calculated $F$ value of the model developed should not exceed the standard tabulated $F$ value. The standard tabulated $F$ value for $95 \%$ confidence limit is 4.06 . Seeing that shown in Table 5, the calculated $F$ value of the model is 2.15 for lack-of-fit is smaller than the standard value of $95 \%$ confidence limit. Thus, it is found that the above model is adequate.

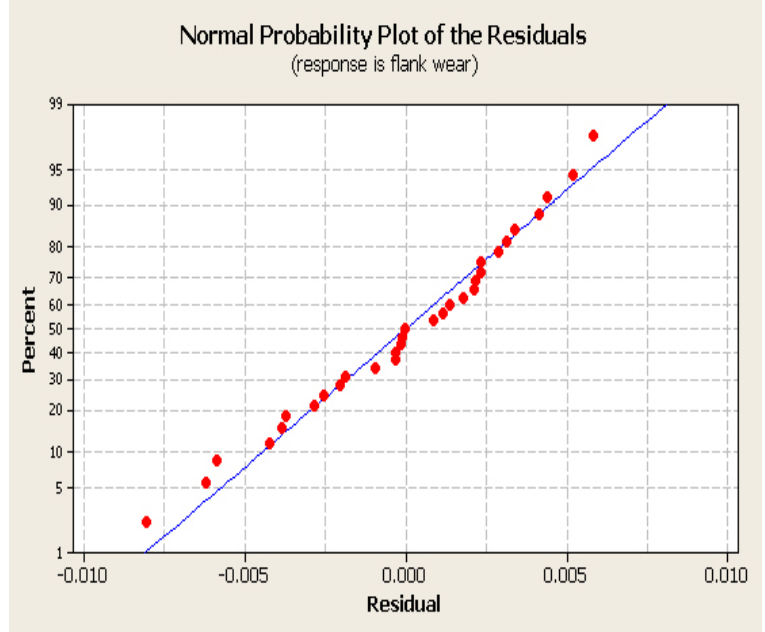

Fig. 1. Normal probability plot of residuals for flank wear data

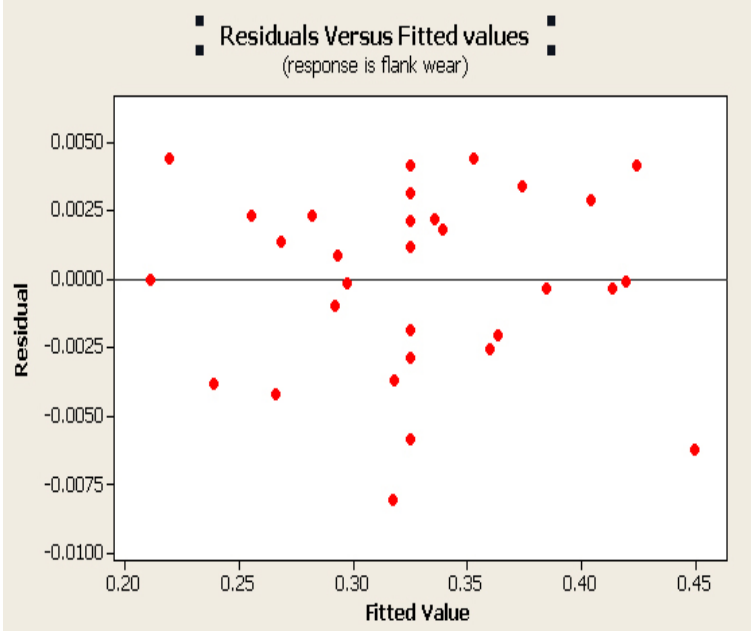

Fig. 2. Plot of residuals vs the fitted values for flank wear

The plot of normal probability of the residual, the plots of the residuals versus the fitted values for tool flank wear is shown in Fig. 1 and 2 respectively. From the normal probability plot of residuals (i.e error = predicted value from model - actual value) in Fig. 1, it is evident that the residuals lie reasonably close to a straight line implying that errors are distributed normally (Kumar et al. 2007). This gives support that terms mentioned in the model are significant. In addition, Fig. 2 revealed that there is no noticeable pattern or unusual structure present in the data. Hence, the RSM model developed is significant \& adequate.

\section{Optimizing end milling process parameters}

The response surface methodology (RSM) was used to optimize the process parameters in this study. RSM is a collection of mathematical and statistical techniques that are useful for designing a set of experiments, developing a mathematical model, analyzing the optimum combination of input parameters, and expressing the values graphically (Khuri et al. 1996). To obtain the influencing nature and optimized condition of the process parameters on tool flank wear, contour plots are the indications of possible independence of factors were developed for the proposed empirical relation by considering two parameters in the middle level and two parameters in the $X$ and $Y$-axis as shown in Fig 3. These response contours can help to predict the response $\left(\mathrm{VB}_{\max }\right)$ for any zone of the experimental domain (Tien et al. 2006). Contour plot plays a very important role in the study of a response surface. It is clear from Fig. 3 that the tool flank wear decreases with the decrease of spindle speed, \%wt. of $\mathrm{SiC}_{\mathrm{p}}$ and feed rate. 
By analyzing the contour plots (Fig. 5), the minimum tool flank wear value is found to be $0.211 \mathrm{~mm}$. The corresponding process parameters that yielded this minimum value are spindle speed of $3000 \mathrm{RPM}$, feed rate of $0.04 \mathrm{~mm} / \mathrm{rev}$, depth of cut of $1.5 \mathrm{~mm}$, and \%wt. of silicon carbide of $5 \%$.
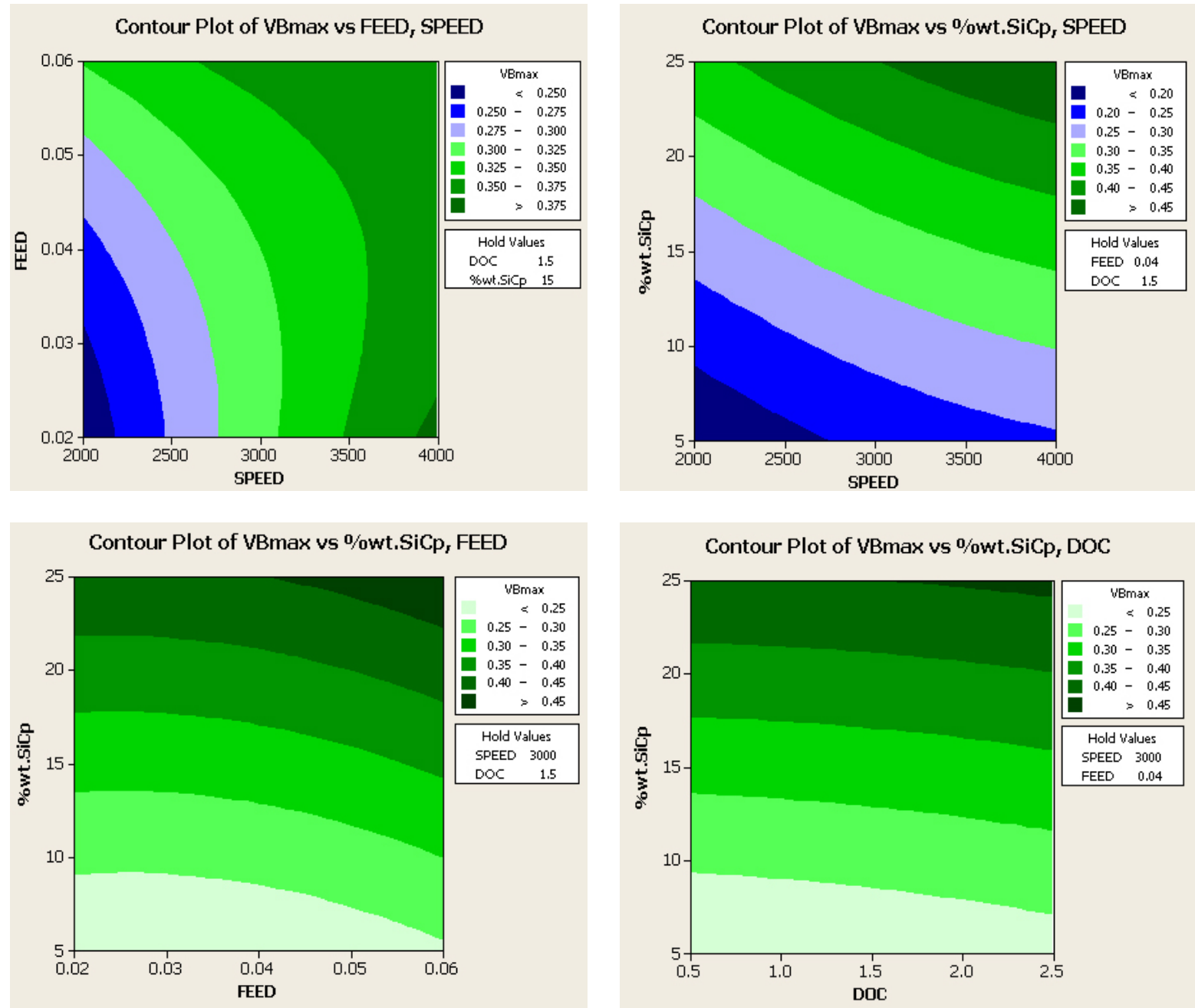

Fig. 3. contour plots

Fig. 4 shows the flank wear contours in spindle speed-feed rate planes at constant depth of cut of $1.5 \mathrm{~mm}$ and different \%wt. of $\mathrm{SiC}_{\mathrm{p}}$.
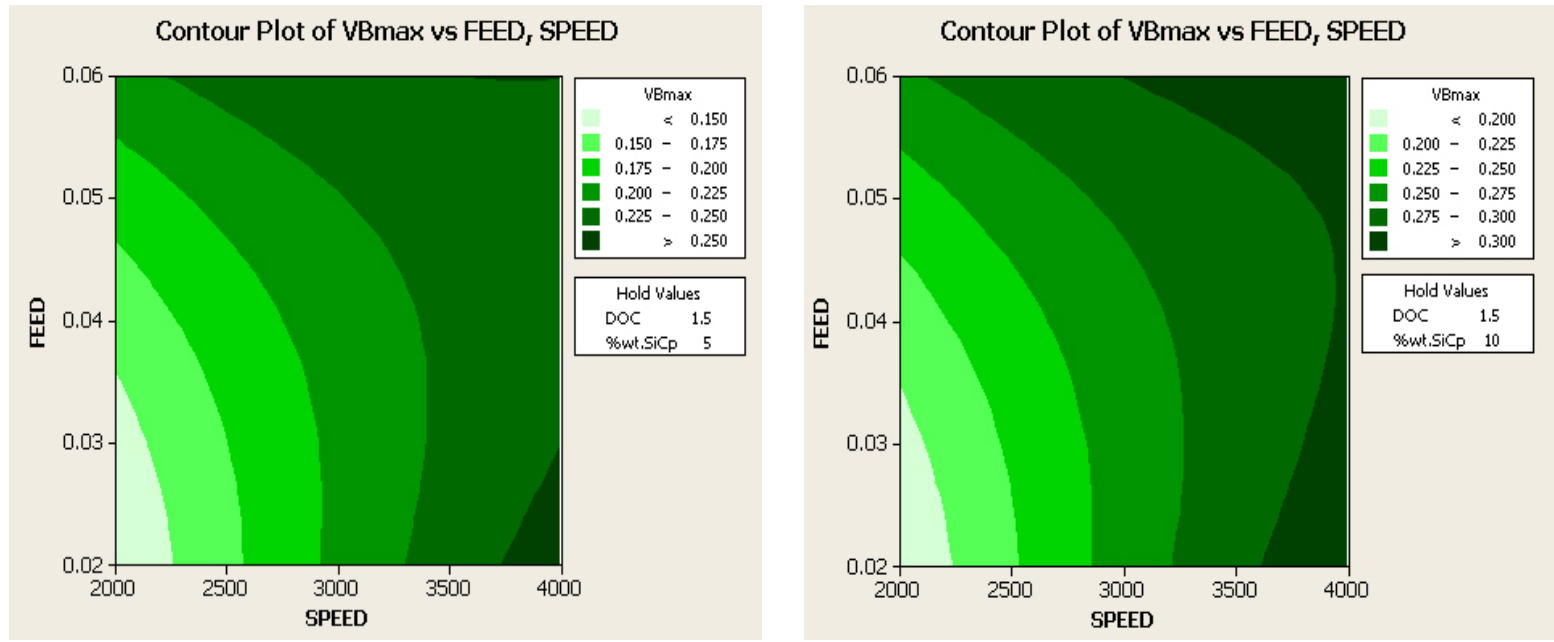

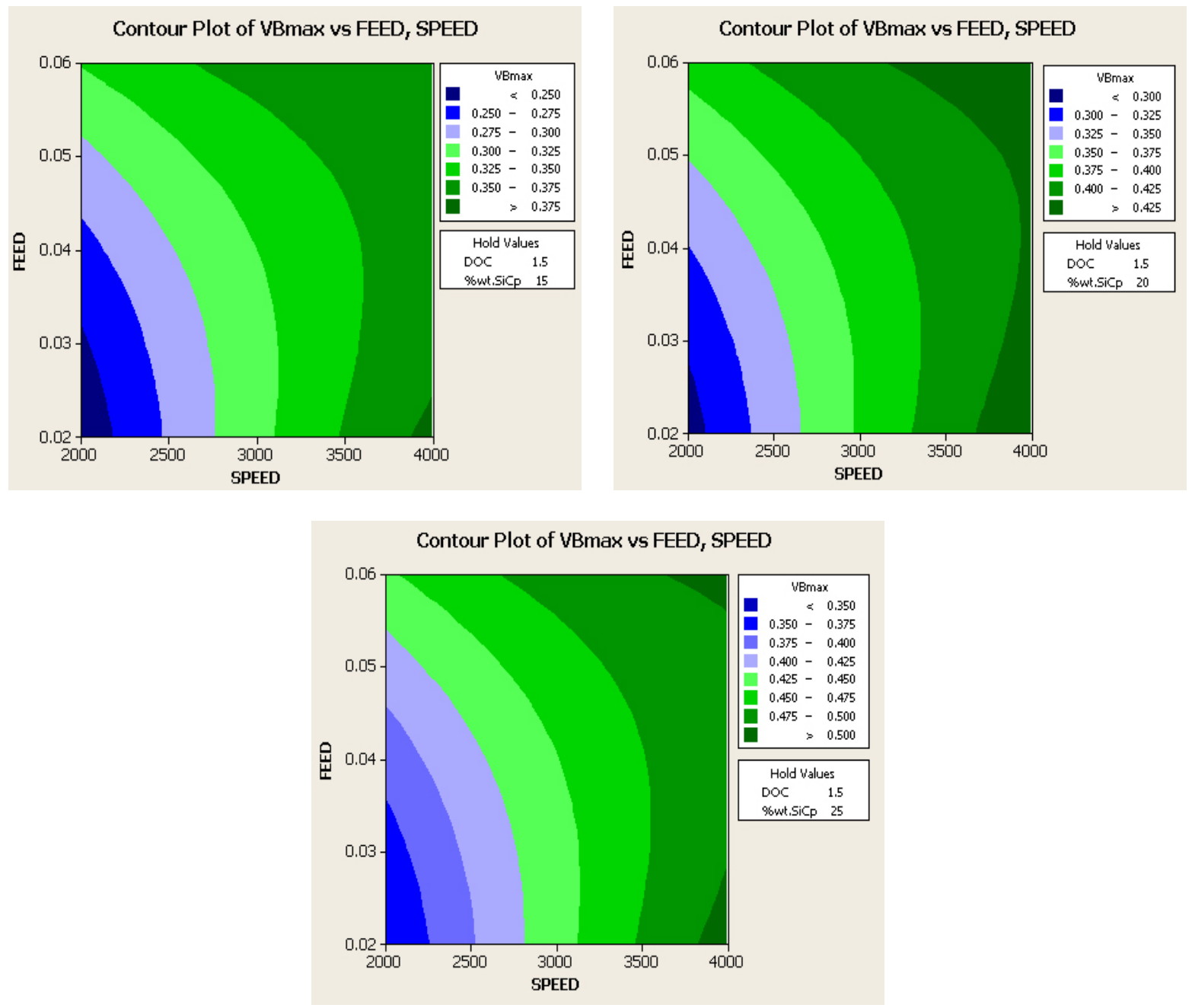

Fig. 4. Flank wear contours in spindle speed-feed rate planes at constant depth of cut of $1.5 \mathrm{~mm}$ and $\mathrm{SiC}_{\mathrm{p}}$ (a) $5 \%$ wt. (b) $10 \%$ wt. (c) $15 \%$ wt. (d) $20 \%$ wt. and (e) $25 \%$ wt.

It is evident from contour figures increasing the percentage of the $\mathrm{SiC}$ particles also increases the tool wear because of increasing the surface contact between the $\mathrm{SiC}$ particles and the cutting tool edge in higher percentage of the SiC particles. From the $p$ values (Table 4), it can be concluded that spindle speed and $\%$ wt. of $\mathrm{SiC}_{\mathrm{p}}$ contributes more to tool flank wear followed by feed rate in the considered range in this investigation. Depth of cut has minimum influence on the tool flank wear.

\section{Conclusions}

1. An empirical relationship was developed to predict the tool flank wear of end milling of LM 25 $\mathrm{Al} / \mathrm{SiCp}$, incorporating process parameters. The developed relationship can be effectively used to predict the tool flank wear of carbide tool at a confidence level of $95 \%$.

2. A minimum tool flank wear of $0.211 \mathrm{~mm}$ could be attained under the process parameters: $3000 \mathrm{RPM}$ of spindle speed, $0.04 \mathrm{~mm} / \mathrm{rev}$ of feed rate, $1.5 \mathrm{~mm}$ of depth of cut, and $5 \%$ of silicon carbide.

3. Spindle speed and \%wt. of $\mathrm{SiC}_{\mathrm{p}}$ were found to have greater influence on tool flank wear in end milling of $\mathrm{LM} 25 \mathrm{Al} / \mathrm{SiC}_{\mathrm{p}} \mathrm{MMC}$, followed by feed rate. Depth of cut has minimum influence on the tool flank wear.

4. The experimental values were compared with the predicted values and error less than 5 percent is observed. 
5. Increasing the percentage weight of the $\mathrm{SiC}_{\mathrm{p}}$ also increases the tool wear because of increasing the surface contact between the $\mathrm{SiC}_{\mathrm{p}}$ and the cutting tool edge in higher percentage weight of the $\mathrm{SiC}_{\mathrm{p}}$.

\section{Acknowledgements}

The authors thank Mr. Rajasekar for his kind technical and experimental help. I also would like to place my sincere gratitude to Mr. Earnest Paul for proof reading.

\section{References}

Allison, J.E., \& Gole, G.S. (1993). Metal-matrix composites in the automotive industry opportunities and challenges. Journal of Minerals, Metallurgy and Materials, 45(1), 19-24.

Chennakesavarao, B., Reddy, P.N. Komariah, N. \& Malla, R.D. (2000). Machinability of vacuum hot pressed metal matrix composites. Proceedings of the Seventeenth AIMTDR Conference, R.E.C. Warangal. 53.

Dabade, U.A., Joshi, S.S., Balasubramaniam, R., \& Bhanuprasad, V.V. (2007).Surface finish and integrity of machined surfaces on $\mathrm{Al} / \mathrm{SiC}_{\mathrm{p}}$ composites. Material Processing Technology, 192-193,166.

Davim, J.P. (2003).Design of optimization of cutting parameters for turning metal matrix composites based on the orthogonal arrays. Material Processing Technology, 132, 340.

Ghosh, N., Ravi, Y.B., A. Patra, A., Mukhopadhyay, S., Paul, S., Mohanty, A.R., \& Chattopadhya, A.B. (2007). Estimation of tool wear during CNC milling using neural network-based sensor fusion. Mechanical Systems and Signal Processing 21, 466-479.

Kenned, F.E., Balbahadu, A.C., \& Lashmore, D.S. (1997). The friction and wear of Cu-based silicon carbide particulate metal matrix composites for brake applications. Wear, 203/204, 715-721.

Khuri, A.I., Cornell, J., (1996). Response surfaces design and analysis [M]. New York, Marcel Dekker.

Ko, T. J.,\& Cho, D. W., (1993). Estimation of tool wear length in finish milling using a fuzzy inference algorithm.Wear, 169, 97-106.

Kumar, S., Kumar, P., \& Shan, H.S. (2007).Effect of evaporative pattern casting process parameters on the surface roughness of Al-7\% Si alloy castings. Material Processing Technology, 182, 615-623.

Murti, K.G., \& Sunderesan, S., (1986).Structure and properties of friction welds between high-speed steel and medium carbon steel for bimetal tools. Material Science Technology, 2, 865-870.

Ning, L., \& Veldhuis, C., (2006).Mechanistic Modeling of Ball End Milling Including Tool Wear. Manufacturing Processes 8, 21-28.

Ozel, T., \& Nadgir,A., (2002). Prediction of flank wear by using back propagation neural network modeling when cutting hardened H-13 steel with chamfered and honed CBN tools. Machine Tools \& Manufacture, 42, 287-297.

Palanikumar, K., \& Davim, J.P. (2009). Assessment of some factors influencing tool wear on the machining of glass fibre-reinforced plastics by coated cemented carbide tools. Material Processing Technology, 209, 511-519.

Palanikumar, K. \& Karthikeyan, R. (2007).Assessment of factors influencing surface roughness on the machining of $\mathrm{Al} / \mathrm{SiC}$ particulate composites. Mater.Des., 28, 1584-1591.

Ravikiran, A., \& Surappa, M.K. (1997). Effect of sliding speed on wear behavior of A356 Al 30 wt \% SiCp MMC. Wear, 206, 33-38.

Tien,C.L., Lin S.W. (2006).Optimization of process parameters of titanium dioxide films by response surfaces methodology. Optics Communications, 266, 574-581.

Yuan, Z.J., \& Dong, G.S. (1993). Ultra precision machining of SiCw/Al composites. CRIP Ann., 42(1), 107. 